\title{
KELIMPAHAN DAN KELIMPAHAN RELATIF DUNG BEETLE DI HUTAN PENDIDIKAN KONSERVASI TERPADU UNIVERSITAS LAMPUNG PADA BLOK LINDUNG TAHURA WAN ABDUL RACHMAN ABUNDANCE AND RELATIVE ABUNDANCE OF DUNG BEETLE SPECIES IN THE INTEGRATED CONSERVATION FOREST OF LAMPUNG UNIVERSITY IN THE PROTECTED BLOCK TAHURA WAN ABDUL RACHMAN
}

\author{
Dewi Ira Rahmawati ${ }^{*}$, Bainah Sari Dewi ${ }^{1}$, Sugeng P. Harianto ${ }^{1}$, Nuning Nurcahyani ${ }^{2}$ \\ 1) Jurusan Kehutanan, Fakultas Pertanian, Universitas Lampung \\ 2) Jurusan Biologi, Fakultas MIPA, Universitas Lampung \\ Jl. Prof. Dr. Ir. Sumantri Brojonegoro, Gedong Meneng, Kec. Rajabasa, Kota \\ Bandar Lampung, Lampung 35141 \\ *E-mail: Dewiirarahmawati1@gmail.com
}

Received: 10th July 2019; Revised: 06th September 2019;

Accepted: 7 th October 2019

\begin{abstract}
ABSTRAK
Kelimpahan dan kelimpahan relatif dung beetle berperan penting sebagai bioindikator kerusakan hutan dan habitat. Tujuan penelitian untuk menganalisis kelimpahan spesies dan kelimpahan relatif spesies dung beetle di Hutan Pendidikan Konservasi Terpadu Universitas Lampung Blok Lindung, Tahura Wan Abdul Rachman pada Desember 2018-Februari 2019. Metode yang digunakan adalah metode trap, kemudian data yang terkumpul dianalisis dengan indeks kelimpahan dan indeks kelimpahan relatif. Hasil penelitian menunjukkan bahwa kelimpahan spesies dung beetle termasuk sedang dengan nilai 3,53 yang menggambarkan keadaan Hutan Pendidikan Tahura Wan Abdul Rachman masih tergolong baik. Ada empat jenis dung beetle yang ditemukan yaitu Catharsius molossus, Onthophagus sp, Aphodius marginellus dan Oryctes rinocheros. Kelimpahan relatif seluruhnya termasuk tinggi dengan nilai di atas $20 \%$ hal ini karena jumlah setiap jenis dung beetle yang ditemukan hampir sama. Pengelola sebaiknya menjaga kelestarian hutan dengan mencegah terjadinya penebangan liar.
\end{abstract}

Kata kunci: Dung beetle, Scarabaeidae, Kelimpahan, Kelimpahan relatif. 


\begin{abstract}
Abundance and relative abundance of dung beetle role as a bioindicator of forest and habitat damage. The purpose of the study was to analyze the abundance of species and the relative abundance of dung beetle species in the Integrated Conservation Forest of Lampung University in the Protected Block, Tahura Wan Abdul Rachman on December 2018-February 2019. The method used was the trap method, then the collected data were analyzed by abundance index and relative abundance index. The results showed that the abundance of dung beetle was moderate with a value of 3.53 which described the condition of the Forest of Education in Tahura Wan Abdul Rachman was still relatively good. There are four types of dung beetle found, consist of Catharsius molossus, Onthophagus sp, Aphodius marginellus and Oryctes rinocheros. The relative abundance is high with values above $20 \%$ because the number of each type of dung beetle found is almost the same. Managers should preserve forests by preventing illegal logging.
\end{abstract}

Keywords: Dung beetle, Scarabaeidae, abundance, relative abundance.

\title{
PENDAHULUAN
}

Dung beetle merupakan suatu kelompok serangga di dalam famili Scarabaeidae yang dikenal dengan hidupnya di sekitar tinja (Helmiyetti et al. 2015). Serangga ini memiliki ukuran tubuh yang berbeda-beda dan bersarang di dalam tanah dengan cara menggalinya. Sarang yang dangkal dibuat oleh dung beetle yang berukuran kecil, sedangkan sarang yang dalam dibuat oleh dung beetle yang berukuran besar (Bui et al. 2018). Sebagian besar Scarabaeidae berasosiasi dengan kotoran mamalia (sapi, kerbau, gajah, rusa dan beruang). Hal tersebut juga dinyatakan oleh Dewi et al. (2018) bahwa mamalia dan dung beetle berkaitan erat, karena dung beetle sangat bergantung pada tinja mamalia sebagai substrat dan sumber pakan untuk bereproduksi.

Menurut Helmiyetti et al. (2015) dung beetle di hutan dapat berfungsi sebagai pendegradasi materi organik yang berupa tinja satwa liar terutama mamalia. Serangga tersebut menguraikan tinja menjadi partikel dan senyawa sederhana dalam proses yang dikenal dengan daur ulang unsur hara atau siklus hara. Peran lainnya dalam ekosistem yaitu sebagai agen pengendali hayati yang efektif untuk parasit pada saluran pencernaan satwa. Telur-telur parasit ikut tercampur dalam kotoran dan berkembang sampai menjadi stadium infektif, yang kemudian berpindah ke rerumputan lalu termakan oleh satwa. Apabila satwa memakan telur parasit, maka siklus hidup parasit terputus. Pada umumnya dung beetle menjadi salah satu indikator terhadap tingkat kerusakan hutan tropis dan habitat serta struktur komunitas dan distribusi sangat dipengaruhi oleh tingkat penutupan vegetasi dan struktur fisik hutan (Widhiono et al. 2017).

Kelimpahan dung beetle sangat berpengaruh penting terhadap lingkungan. Hal ini karena serangga tersebut bersifat sensitif terhadap perubahan vegetasi, iklim mikro dan satwa yang ada di habitatnya (Muhaimin et al. 2015; Malina et al. 2018). Dung beetle juga membantu proses penyebaran biji tumbuhan (Sari et al. 2015; Latha dan Sabu 2018), dan penting sebagai indikator biologi, apabila berada di lingkungan yang berbeda, maka akan mempunyai struktur dan distribusi yang berbeda pula (Dewi et al. 2018). Penyebaran dan penguraian tinja 
dibantu oleh perilaku makan dan reproduksi yang dilakukannya di sekitar tinja, sehingga tidak menumpuk di suatu tempat. Tinja yang dibiarkan di permukaan tanah dapat mematikan atau memperlambat pertumbuhan tanaman maupun rumput. Salah satu tempat ditemukan dung beetle ialah Hutan Pendidikan Konservasi Terpadu (HPKT) Universitas Lampung (Unila) pada Blok Lindung di Tahura Wan Abdul Rachman (Tahura WAR). Tujuan penelitian untuk menganalisis kelimpahan spesies dan kelimpahan relatif spesies dung beetle di HPKT Unila pada Blok Lindung Tahura WAR.

\section{METODOLOLOGI PENELITIAN}

Penelitian ini dilakukan pada Desember 2018 sampai Februari 2019 di Arboretum VII - XII HPKT Unila pada Blok Lindung Tahura WAR. Objek penelitian yang digunakan yaitu dung beetle dan alat yang digunakan berupa cangkul, trap (jebakan) yang terbuat dari ember yang berukuran \pm 1 liter yang berisi air $\pm 500 \mathrm{ml}$ dan gelas plastik yang berisi feses sapi, kambing dan rusa, kawat untuk mengaitkan gelas plastik, dan kamera. Peta lokasi dapat dilihat pada Gambar 1.

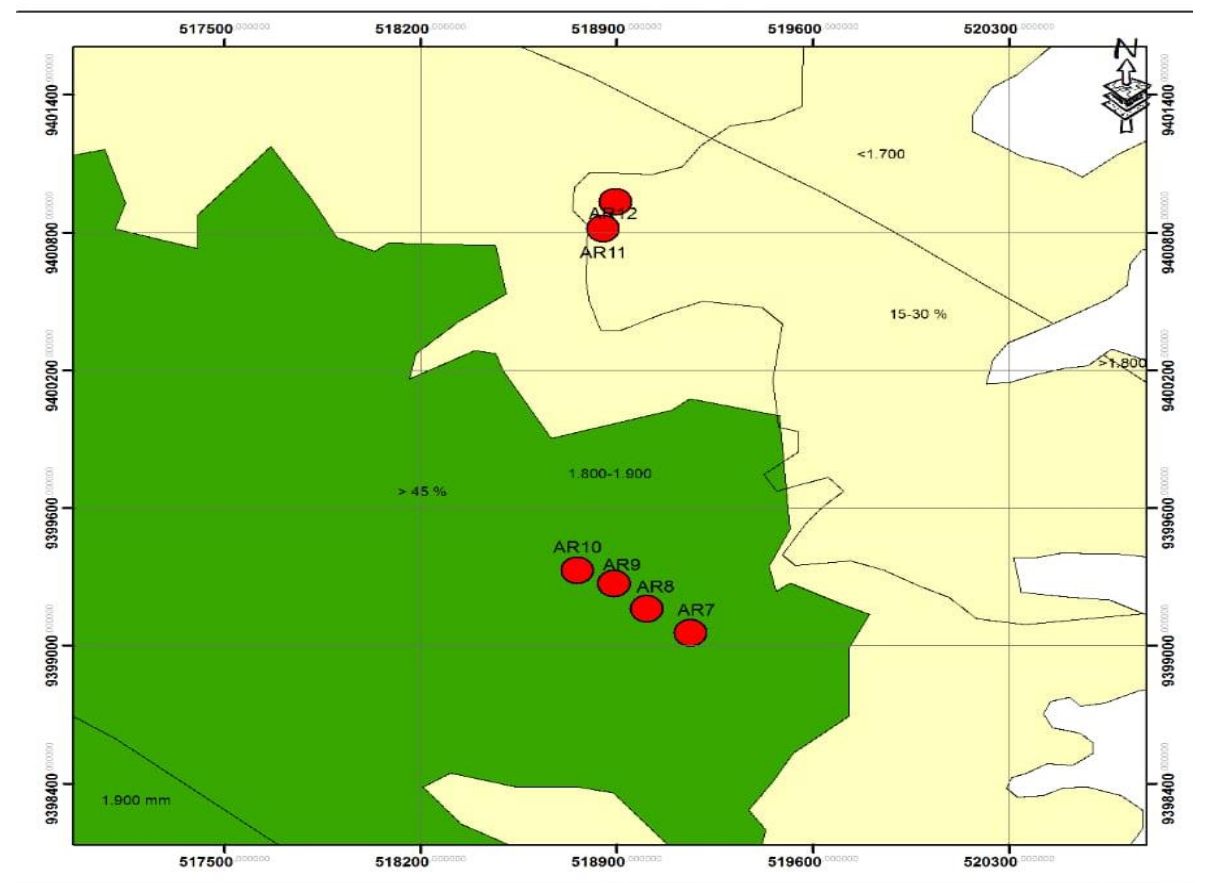

\section{Legenda}
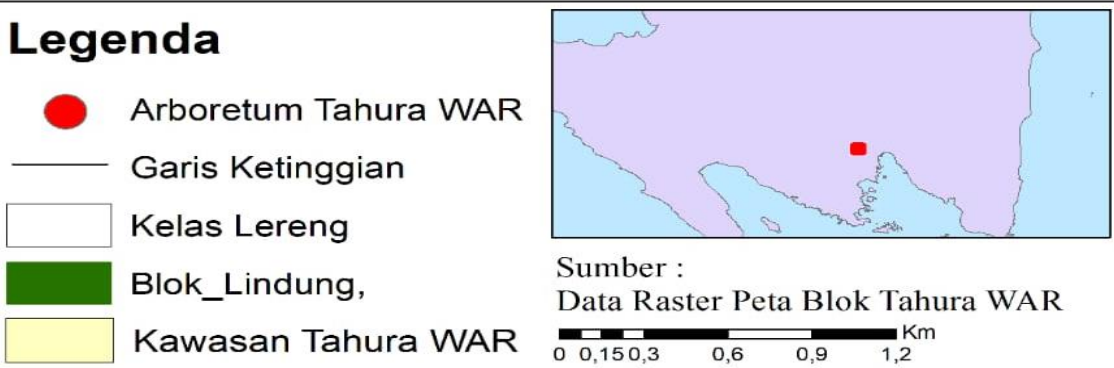

Gambar 1. Peta HPKT Unila pada Blok Lindung Tahura WAR dengan skala 1: 20.000 (Riyanto 2019) 
Jenis data yang dikumpulkan adalah data primer dan sekunder. Data primer meliputi kelimpahan dung beetle di HPKT Unila. Data sekunder yang digunakan meliputi informasi mengenai gambaran umum lokasi, studi literatur, dan hasil-hasil penelitian terdahulu. Data primer yang didapatkan kemudian dihitung menggunakan rumus indeks kelimpahan (Margalef 1958; Alhani et al. 2015; Adelia et al. 2016) sebagai berikut:

$$
\mathrm{R}=\frac{S-1}{\operatorname{Ln} N}
$$

dimana :

$\mathrm{R} \quad=$ indeks kelimpahan jenis

$\mathrm{S} \quad=$ jumlah total jenis dalam suatu habitat

$\mathrm{N}=$ jumlah total individu dalam suatu habitat

dengan kriteria :

$\mathrm{R}<2,5=$ menunjukkan kelimpahan jenis yang rendah

$2,5>\mathrm{R}>4=$ menunjukkan tingkat kelimpahan jenis yang sedang

$\mathrm{R}>4=$ menunjukkan tingkat kelimpahan jenis yang tinggi

Perhitungan Indeks Kelimpahan Relatif (IKR) menggunakan rumus di bawah ini (Krebs 1989) sebagai berikut:

$$
\operatorname{IKR}=\frac{\text { jumlah individu suatu spesies }\left(n_{i}\right)}{\text { jumlah total individu yang ditemukan }(n)} \times 100 \%
$$

Nilai indeks kelimpahan relatif digolongkan dalam tiga kategori yaitu tinggi (>20\%), sedang (15\%-20\%), dan rendah (<15\%) (Ismawan et al. 2015; Asrianny et al. 2018).

\section{Gambaran Umum Lokasi}

\section{HASIL DAN PEMBAHASAN}

Tahura Wan Abdul Rachman terletak di Provinsi Lampung. Berdasarkan Surat Keputusan Penetapan Tata Batas Nomor:408/Kpts-II/1993 Tahura WAR ditetapkan dengan luas 22.249,31 ha. Pihak Tahura WAR memberikan amanah melalui MOU antara Universitas Lampung dan Dinas Kehutanan untuk menjadikan Tahura WAR sebagai Hutan Pendidikan Konservasi Terpadu Universitas Lampung dengan luas 1.143 ha (Puslitbang Tropika Unila 2017).

Kawasan Tahura WAR terbagi menjadi beberapa blok pengelolaan antara lain Blok Perlindungan, Blok Koleksi Tumbuhan, dan Blok Pemanfaatan dan dimanfaatkan oleh masyarakat sekitar hutan (Febryano 2008; Febryano et al. 2009; Kristin et al. 2018). Menurut Erwin et al. (2017), Tahura WAR memiliki 
sekitar 728 spesies flora. juga memiliki keanekaragaman fauna yang tinggi, seperti yang ditemukan dalam penelitian Zulkarnain et al. (2018) yaitu napu (Tragulus napu), tupai (Tupaia sp), beruk (Macaca nemestrina), siamang (Hylobates syndactylus), beruang madu (Helarctos malayanus), monyet ekor panjang (Macaca fascicularis) dan babi hutan (Sus scrofa).

Tahura WAR berfungsi sebagai perlindungan sistem penyangga kehidupan, pengawetan keanekaragaman jenis tumbuhan dan satwa serta ekosistemnya, pemanfaatan secara lestari sumber daya alam hayati dan ekosistemnya. Berdasarkan penelitian Erwin et al. (2017) di HPKT Unila terdapat 60 spesies pohon yang tercakup dalam 22 famili, beberapa diantaranya adalah tanaman MPTS (Multi Purpose Tree Species). Hutan ini membentuk sistem Agroforestri antara tanaman hutan dan tanaman pertanian, salah satu tanaman pertaniannya adalah tanaman cabai. Tanaman MPTS di lokasi ini berbuah sesuai dengan musimnya. Satwa liar yang berada disana bertahan hidup karena ketersediaan pakan, sehingga hasil feses satwa tersebut menjadi sumber pakan dung beetle.

\section{Kelimpahan dan Kelimpahan Relatif Dung beetle}

Nilai kelimpahan spesies dung beetle yang ditemukan tergolong dalam kategori sedang (Tabel 1) yang menunjukkan bahwa spesies dung beetle yang berada di HPKT Unila memiliki persebaran yang masih merata. Hal ini disebabkan adanya ketersediaan pakan bagi spesies tersebut. Pakan dapat tersedia karena populasi mamalia banyak dan tersebar di HPKT Unila, populasi mamalia bertahan hidup dengan ketersediaan pakan yang berupa vegetasi bawah dan pohon yang memiliki buah yang ada di Tahura WAR khususnya Blok Lindung. Kondisi ini dapat menggambarkan bahwa HPKT Unila masih memiliki keadaan hutan yang cukup bagus dan memiliki vegetasi yang relatif tertutup. Faktor lain yang mempengaruhi kelimpahan yaitu kelembaban udara dalam suatu ekosistem. Kelembaban udara dapat terjaga karena tutupan tajuk di HPKT Unila masih rapat dan belum mengalami gangguan. Sejalan dengan penelitian Helmiyetti et al. (2015) bahwa dung beetle lebih menyukai kondisi lingkungan yang lembab. Keberadaan dung beetle dipengaruhi oleh adanya keberadaan hewan (mamalia), jenis tanah, vegetasi bentuk kanopi tumbuhan dan cahaya.

Tabel 1. Kelimpahan Spesies Dung Beetle.

\begin{tabular}{llcccc}
\hline \multirow{2}{*}{ No } & \multirow{2}{*}{ Nama Spesies } & \multicolumn{3}{c}{ Jumlah ditemukan } & Abundance \\
\cline { 2 - 4 } & & Desember & Januari & Februari & Kelimpahan \\
\hline 1 & Catharsius molossus & 3 & 4 & 2 & \\
2 & Onthopagus sp & 3 & 3 & 2 & 3,53 \\
3 & Aphodius marginellus & 2 & 3 & 4 & \\
4 & Oryctes rinocheros & 2 & 2 & 4 & \\
\hline \multicolumn{2}{l}{ Jumlah Jenis } & \multicolumn{5}{c}{4} \\
\hline
\end{tabular}

Kondisi vegetasi dapat mempengaruhi keberadaan dung beetle serta menciptakan suhu dan kelembaban. Hal tersebut dapat mempengaruhi, mendukung aktivitas dung beetle dan kualitas kotoran hewan yang tersedia 
dalam suatu habitat. Kualitas kotoran hewan pada kondisi vegetasi yang rapat dapat menyebabkan terjaganya kelembaban tinja satwa. Kelembaban tinja tersebut mengudang dung beetle untuk hinggap dan menjalankan aktivitasnya. Tinja yang lembab memiliki aroma yang lebih menyengat dibandingkan tinja yang sudah kering. Menurut penelitian Ueda et al. (2015); Aruchunnan et al. (2016); Dewi et al. (2017), apabila hutan telah mengalami kerusakan yang begitu parah seperti pengalihan fungsi lahan dari lahan tertutup menjadi lahan terbuka, maka tidak akan ditemukan spesies tersebut lagi. Hal ini karena dung beetle tidak menyukai cuaca yang panas. Sejalan dengan penelitian Helmiyetti et al. (2015) bahwa salah satu bioindiktor tingkat kerusakan hutan tropis dan habitat adalah dung beetle, karena struktur komunitas dan distribusinya sangat dipengaruhi oleh tingkat penutupan vegetasi dan struktur fisik hutan. Kondisi demikian mengharuskan habitat dung beetle tetap terjaga kelestariannya. berikut:

Ada empat jenis dung beetle yang ditemukan dengan deskripsi sebagai

\section{Aphodius marginellus}

Aphodius marginellus memiliki tubuh berwarna cokelat dengan punggung yang cembung, panjang tubuh sekitar $12 \mathrm{~cm}$. Kaki berbentuk khas sebagai penggali. Spesies ini banyak ditemui pada musim hujan dan pada trap yang ternaungi tajuk. Kaszyca dan Taszakowski (2017); Dewi et al. (2018) menjelaskan bahwa dung beetle hidup pada tinja dan tersebar di daerah tropis. Dikenal suka menggelindingkan bola-bola yang terbuat dari kotoran yang berbobot 50 kali lebih berat dibandingkan tubuhnya sendiri. Spesies tersebut juga menggunakan kotoran sebagai pendingin tubuh (Gambar 2).

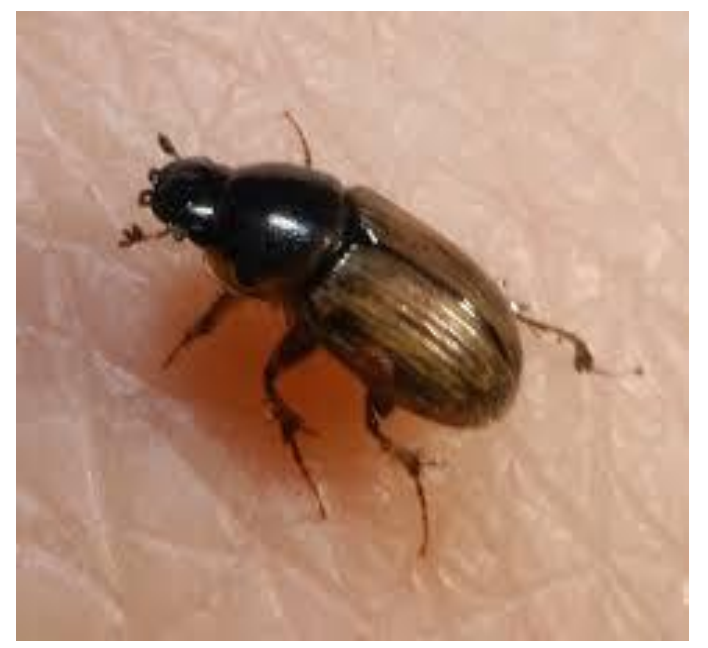

Gambar 2. Aphodius marginellus.

\section{Cattarsius mollosus}

Catharsius mollosus adalah kumbang yang berukuran besar $(30-35 \mathrm{~mm})$, memiliki tiga pasang kaki, bentuk tubuh bulat dan pada bagian kepala terdapat antena dan lebih banyak aktivitasnya pada malam hari. Ketika dewasa kumbang memiliki tanduk sehingga mempermudah dalam menggali tanah. Meskipun 
tempat yang tertutup naungan disukai, kumbang ini juga mampu beradaptasi padanaungan terbuka. Menurut Ma et al. (2015); Lu et al. (2015) Catharsius molossus adalah spesies yang berasal dari genus Catharsius, memiliki peran penting di ekosistem dan berpotensi menjadi bahan obat (Gambar 3).

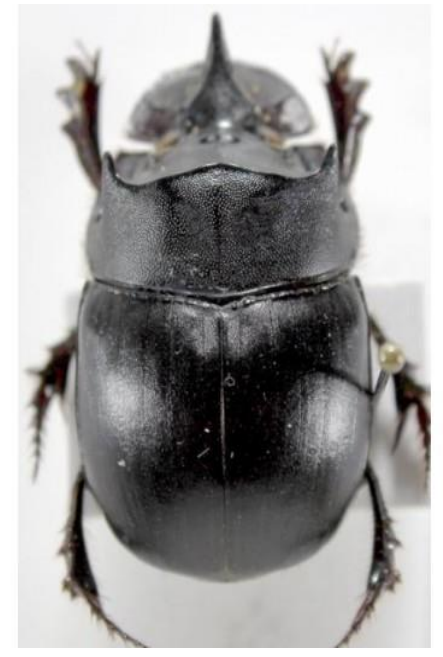

Gambar 3. Catharsius molossus.

\section{Oryctes rhinoceros}

Oryctes rhinoceros memiliki tubuh berwarna cokelat tua dengan tiga pasang kaki, tubuh berbentuk cembung dan terdapat tanduk yang panjangnya sekitar 1 $\mathrm{cm}$. Kumbang dapat bertahan hidup selama dua hari di dalam trap. Dung beetle ini tidak hanya hidup di sekitar tinja akan tetapi dapat bertahan hidup juga di palem-paleman. Menurut Bintang et al. (2015); Handoko et al. (2017); Fauzana et al. (2018) spesies tersebar luas di Asia Tenggara ke Timur sampai Pulau Irian hingga Pulau Formosa. Tanduk pada kumbang jantan lebih panjang dan melengkung ke belakang, sedangkan tanduk kumbang betina berupa tonjolan, tanduk pada kumbang ini berfungsi untuk pertahanan diri (Gambar 4).

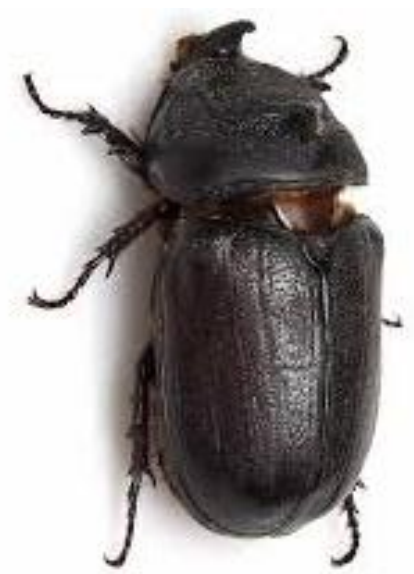

Gambar 4. Oryctes rhinoceros. 


\section{Onthopagus sp}

Onthopagus sp memiliki ukuran tubuh berkisar $11 \mathrm{~cm}$, memiliki antena pada kepalanya, warna tubuh cokelat gelap serta memiliki tiga pasang kaki. Ketika sudah terjebak di dalam trap hanya mampu bertahan hidup satu hari. Spesies ini lebih sering dijumpai dalam keadaan membenamkan diri ke dalam tinja untuk mendinginkan tubuh, karena dung beetle ini tidak menyukai cuaca yang panas. Hal tersebut sejalan dengan penelitian Mario dan Gonzalo (2019) bahwa Onthopagus sp termasuk filum Arthopoda yang hidup di tempat lembab dan membenamkan diri pada tinja (Gambar 5).

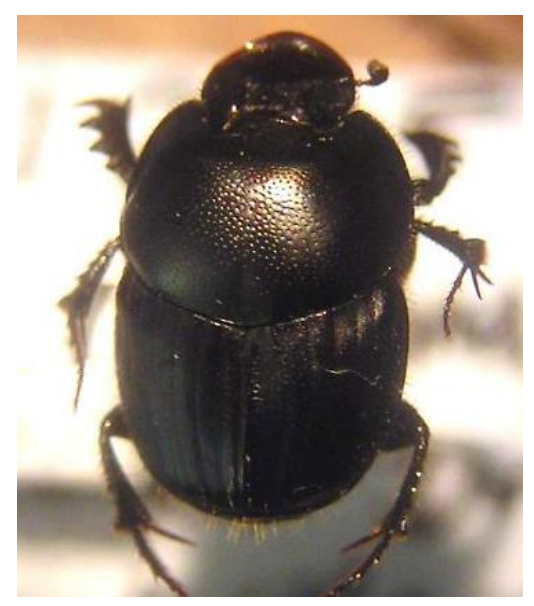

Gambar 5. Onthopagus sp.

Persentase Kelimpahan Relatif (KR) dung beetle dari ke empat jenis termasuk tinggi (Gambar 6). Jumlah individu dari setiap jenis dung beetle yang ditemukan tidak berbeda jauh, yaitu Catharsius molossus 9 individu, Onthopagus sp 8 individu, Aphodius marginellus 9 individu dan Oryctes rhinoceros 8 individu. Oleh karena itu, persentase kelimpahan relatifnya tidak berbeda jauh. Jenis dung beetle yang paling mendominasi yaitu Catharsius molossus dan Aphodius marginellus. Kedua spesies ini diduga mudah beradaptasi. Meski lebih menyukai vegetasi yang terdapat di wilayah tertutup, spesies tersebut juga mampu bertahan hidup pada vegetasi di wilayah terbuka dan dapat menyesuaikan diri terhadap lingkungannya. Sejalan dengan penelitian yang telah dilakukan oleh Helmiyetti et al. (2015), bahwa Aphodius marginellus termasuk jenis kumbang yang lebih menyukai lahan lembab dan tertutup. 


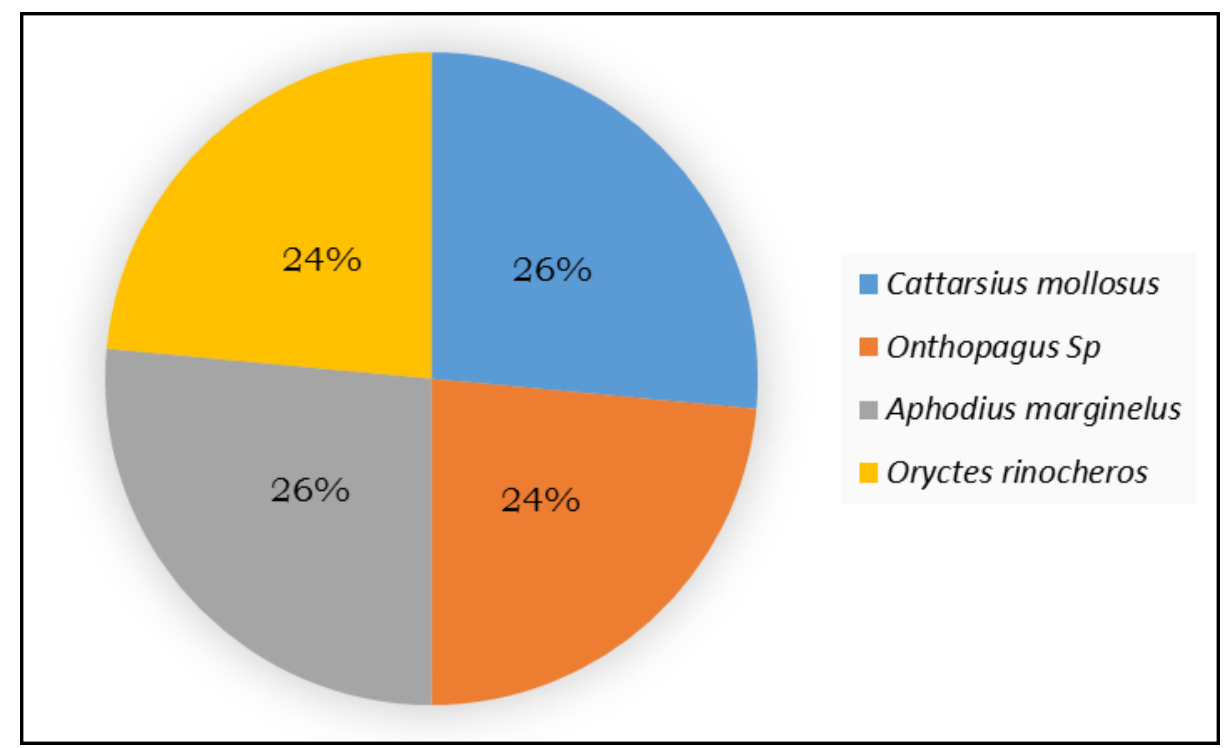

Gambar 6. Kelimpahan Relatif Dung beetle.

\section{PENUTUP}

Kelimpahan dung beetle termasuk sedang, artinya keadaan HPKT Unila tersebut masih baik dan memiliki ketersediaan pakan yang cukup bagi dung beetle. Jenis dung beetle yang ditemukan adalah Catharsius molossus, Onthophagus sp, Aphodius marginellus dan Oryctes rinocheros. Secara keseluruhan kelimpahan relatif dung beetle termasuk tinggi. Hal tersebut menggambarkan jumlah individu yang ditemukan setiap jenis tidak berbeda jauh. Aphodius marginellus dan Catharsius molossus lebih banyak ditemukan karena mampu beradaptasi dengan lingkungan yang berbeda. Pihak pengelola HPKT Unila disarankan untuk mencegah penebangan liar yang menjadi menjadi penyebab rusaknya kelestarian hutan, sehingga dapat mempertahankan keberadaan dung beetle.

\section{UCAPAN TERIMA KASIH}

Penulis mengucapkan terima kasih kepada pihak-pihak yang telah membantu menyelesaikan penelitian yaitu Novia Dewara, Havist Prayoga, Umy Mayasari, Nyimas Dita Maharani, Ary Rahmadi, Kornelius Siahaan, Suci Rahmadhani, Rizky Noviasari dan Dedi Riyanto, serta pihak Tahura Abah Adik, Putra Abah Adik, Pak Saban, Junaidi, dan Agus Tamtomo (polhut).

\section{DAFTAR PUSTAKA}

Adelia, M., Harianto, S.P., dan Nurcahyani, N. 2016. Keanekaragaman Jenis Burung di Hutan Rakyat Pekon Kelungu Kecamatan Kota Agung Kabupaten Tanggamus. Jurnal Sylva Lestari 4(2): 51-60.

Alhani, F., Manurung, T.F., danDarwati, H., 2015. Keanekaragaman Jenis Vegetasi Pohon di Kawasan Hutan dengan Tujuan Khusus (Khdtk) Samboja Kabupaten Kutai Kartanegara Kalimantan Timur. Jurnal Hutan Lestari 3(4): 590-598. 
Aruchunnan, G.Y.F., Hazmi, I.R., dan Wee, S.L. 2016. Dung beetles (Coleoptera:Scarabaeioida) from Tasik Chini Biosphere Reserve, Pahang. Jurnal Serangga 21(1): 147-159.

Asrianny., Saputra, H., dan Achmad, Amran. 2018. Identifikasi Keanekaragaman dan Sebaran Jenis Burunguntuk Pengembangan Ekowisata Bird Watching di Taman Nasional Bantimurung Bulusarang. Jurnal Perennial 14(1): 1723.

Bintang, A.S., Wibowo, A., dan Harjaka, T. 2015. Keanekaragaman Genetik Metarhizium anisopliae dan Virulensinya pada larva Oryctes rhinoceros. Jurnal Perlindungan Tanaman Indonesia 19(1): 12-18.

Bui, V.B., Dumack, K., dan Bonkowski, M. 2018. Two New Species and One New Record for The Genus Copris (Coleoptera:Scarabaeidae:Scarabaeinae) From Vietnam with a Key to Vietnamese Species. European Journal of Entomology 115(3): 167-191.

Dewi, B.S., Harianto, S.P., Rahmawati, D.I., dan Dewara, N. 2018. Biodiversitas Dung beetle di Tahura Wan Abdul Rachman. Sai Wawai, Lampung.

Dewi, B.S., Safei, R., Bintoro, A., Winarno, G.D., dan Santoso, T. 2017. Biodiversitas Flora dan Fauna di Universitas Lampung. Plantaxia, Yogyakarta.

Erwin., Bintoro, A dan Rusita. 2017. Keragaman Vegetasi di Blok Pemanfaatan Hutan Pendidikan Konservasi Terpadu (HPKT) Tahura Wan Abdul Rachman Provinsi Lampung. Jurnal Sylva Lestari 5(3): 1-11.

Fauzana, H., Sutikno, A., dan Salbiah, D. 2018. Population Fluctuations of Oryctes rhinoceros L.Beetle in Plant Oil Palm (Elaeis guineensis Jacq). Given Mulching Oil Palm Empty Bunch. Jurnal Cropsaver 1(1): 42-47.

Febryano, I.G. 2008. Analisis Finansial Agroforestri Kakao di Lahan Hutan Negara dan Lahan Milik. Jurnal Perennial. 4(1): 41-47.

Febryano, I.G., Suharjito, D., dan Soedomo, S. 2009. Pengambilan Keputusan Pemilihan Jenis Tanaman dan Pola Tanam di Lahan Hutan Negara dan Lahan Milik: Studi Kasus di Desa Sungai Langka, Kecamatan Gedong Tataan, Kabupaten Pesawaran. Forum Pascasarjana 32(2): 129-141.

Handoko, J., Fauzana, H., Sutikno, A. 2017. Populasi dan Intensitas Serangan Hama Kumbang Tanduk (Oryctes rhinoceros Linn) Pada Tanaman Kelapa Sawit (Elaeis guineensis Jacq) Belum Menghasilkan. Jom Faperta Unri 4(1): 1-6.

Helmiyetti, S., Manaf., dan Dewi, A.S. 2015. Diversity of Dung Bettle in Cow's Faecal on Kawasan Konservasi Taman Hutan Raya Rajolelo (Tahura) Bengkulu. Jurnal Gradien 11(2): 1 133-1137.

Ismawan, A., Rahayu, S.E., dan Dharmawan, A. 2015. Kelimpahan dan Keanekaragaman Burung di Prevab Taman Nasional Kutai Kalimantan Timur. Jurnal online UM 3(1): 18-25.

Kaszyca, N., dan Taszakowski, A. 2017. Materials to the Knowledge of Scarabaeoidea of the Eastern Beskid Mountain. Acta Entomologica Silesiana 25(13): 1-7.

Krebs, C.J. 1989. Ecological Methodology. Harper and Row Inc Publiser, New York.

Kristin, Y., Qurniati, R., dan Kaskoyo, H. 2018. Interaksi Masyarakat Hutan Terhadap Pemanfaatan Lahan Taman Hutan Raya Wan Abdul Rchman. Jurnal Sylva Lestari 6(3): 1-8. 
Latha, T., dan Sabu, T.K. 2018. Dung beetle (Coleoptera:Scarabaeinae) Community Structure Across a Forest Agriculture Habitat Ecotone in South Western Ghats. International Journal of Environment, Agriculture and Biotechnology 3(5): 1878-1890.

Lu, J., Sun, Q., Tu, Z.C., Qing, L., Shui, P.X., dan Cheng, Y.X. 2015. Identification of N-Acetyldopamine Dimers from the Dung beetle Catharsius Molossus ang Their Cox-1 ang Cox-2 Inhibitory Activities. Molecules Journal 20(1): 15589-15596. Ma, J., Xin, C., dan Tan, C. 2015. Preparation Physicochemical and Pharmaceutical Characterization of Chitosan from Catharsius molossus Residue. International Journal of Biological Macromolecules 1(80): 547-556.

Malina, C. V., Junardi., dan Kustiati. 2018. Spesies Kumbang Kotoran (Coleoptera: Scarabaeidae) di Taman Nasional Gunung Palung Kalimantan Barat. Protobiont 7(2): 47-54.

Margalef, R. 1958. Temporal Succession and Spaital Heterogeneity in Phytoplankton in A.A. Buzzati Traverso (ed.), Perspective in Marine Biology. Univ. California Press, PP. California. 323-349.

Mario, Z., dan Gonzalo, H. 2019. About the Origin of American Onthopagus (Coleoptera: Scarabaeidae). A Critical Appraisal of a Recent Paper by Breeschoten et al. (2016) on Phylogenestics and Biogegography. Molecular Phylogenestics adn Evolution. 133(3): 1-5.

Maulana, A.M.I., Dadi., dan Sopyan, T. 2016. Keanekaragaman Jenis Serangga di Kawasan Hutan Lindung Karangkamulyan Kabupaten Ciamis. Jurnal Pendidikan Biologi 4(1): 82-89.

Muhaimin, A.M.D., Hazmi, I., dan Yaakop, S. 2015. Colonisation of Dung beetles (Coleoptera:Scarabaeidae) of Smaller Body Size in the Bangi Forest Reserve, Selangor, Malaysia: A Model Sampling Site for a Secondary Forest Area. Pertanika journal Tropical Agricultural Science 38(4): 519-532.

Puslitbang Biodiversitas Unila. 2017. Laporan Penelitian di Arboretum Hutan Pendidikan Konservasi Terpadu Tahura Wan Abdul Rachman. Universitas Lampung. Bandar lampung. Tidak dipublikasikan.

Riyanto, D. 2019. Peta Blok Lindung Hutan Pendidikan Konservasi Tahura Wan Abdul Rachman. Bandar Lampung. Tidak dipublikasikan.

Sari, Y.I., Dahlemi., dan Herwina, H. 2015. Jenis-jenis Kumbang Tinja (Coleoptera:Scarabaeidae) di Hutan Pendidikan dan Penelitian Biologi (HPPB) Universitas Andalas, Padang. Jurnal Biologi Universitas Andalas 4(3): 193-199.

Ueda, A., Dwibadra, D., Noerdjito, W.A., Sugiarto., Kon, M., Ochi, T., Takahashi, M., dan Fukuyama, K. 2015. Effect of Habitat Transformation from Grassland to Acacia mangium Plantation on Dung beetle Assemblage in East Kalimantan. Jurnal of Insect Conservation 19(4): 765-780.

Widhiono, I., Darsono., dan Fasihah, N. 2017. Short Communication: Endemics species of dung beetles (Coleoptera: Scarabaeidae) on the southern slope of Mount Slamet, Central Java, Indonesia. Jurnal Biodiversitas 18(1): 283287.

Zulkarnain, G., Winarno, G.D., Setiawan A., dan Harianto, S.P. 2018. Studi Keberadaan Mamalia di Hutan Pendidikan, Taman Hutan Raya Wan Abdul Rachman. Gorontalo Journal of Forestry Research 1(2): 11-20. 